\title{
Lesão central de células gigantes em sínfise mandibular de paciente pediátrico: relato
}

\author{
de caso \\ Central Giant cell injury in the mandibular symphysis of a pediatric patient: case report \\ Lesión central de células gigantes em sínfisis mandibular de paciente pediátrico: reporte de caso
}

Recebido: 07/02/2021 | Revisado: 13/02/2021 | Aceito: 15/02/2021 | Publicado: 22/02/2021

Naiara Sumiye Floris Cardozo Morishita Santos Araújo
ORCID: https://orcid.org/0000-0002-0814-0142
Hospital Municipal Dr. Cármino Caricchio, Brasil
Centro Alfenense de Pós Graduação, CAPO, Brasil
E-mail: naiarafloris@ @ahoo.com.br
Gustavo Paiva Custódio
ORCID: https://orcid.org/0000-0001-6893-369X
Centro Universitário de Volta Redonda, Brasil
E-mail: gustavopaivacustodio@gmail.com
João Pedro Paulino Mazzon
ORCID: https://orcid.org/0000-0003-0224-5805
Hospital Municipal Dr. Cármino Caricchio, Brasil
E-mail: joaopedromazzon@ @hotmail.com
Giuliano Saraceni Issa Cossolin
ORCID: https://orcid.org/0000-0003-4264-2661
Hospital Municipal Dr. Cármino Caricchio, Brasil
E-mail: gcossolin@gmail.com

\section{Resumo}

A lesão central de células gigantes (LCCG) é uma lesão óssea não neoplásica que acomete os ossos gnáticos em pacientes desde a primeira infância até idosos, sendo mais prevalente entre a segunda e terceira década de vida no sexo feminino. A LCCG demonstra uma variação de comportamento agressivo e não agressivo, o que pode refletir diretamente no tratamento estabelecido. Em pacientes pediátricos com dentição mista, uma lesão patológica pode ser a causa subjacente de mobilidade dentária e/ou esfoliação dos dentes decíduos podendo ser negligenciada, especialmente nos casos que não são acompanhados por uma clássica expansão óssea. O presente trabalho objetiva relatar um caso de uma criança de 11 anos, gênero masculino, que na avaliação ortodôntica relatou sensação de movimentação nos dentes mandibulares há aproximadamente dois meses, sem dor e com hipoestesia em lábio inferior. Foi realizada tomografia computadorizada e biópsia incisional para confirmação do diagnóstico e, posterior enucleação, seguida de osteotomia periférica sob anestesia geral. Concluiu-se que a patologia é pouco frequente e possui etiologia desconhecida. É nítido que, apesar de possuir comportamento biológico benigno, pode ser altamente destrutiva, possibilitando diversas formas de condutas cirúrgicas. Seu diagnóstico definitivo depende de avaliações através da análise de exames clínicos, radiográficos, histopatológicos e sorológicos, para abordagem individualizada dentro do quadro clínico apresentado, semelhante a este relato.

Palavras-chave: Cirurgia bucal; Enucleação; Patologia bucal; Doenças ósseas.

\begin{abstract}
The central lesion of giant cells (LCCG) is a non- neoplastic bone lesion that affects gnathic bones in patients from early childhood to the elderly, being more prevalent between the second and third decade of life and in females. It should be taken in to account that, in general, head and neck tumors in childhood generally demonstrate an atypical biological risk. However, the LCCG shows a variety of aggressive and non- aggressive behavior, thus acting directly on the established treatment. In pediatric patients with mixed dentition, a pathological lesion can be the underlying cause of tooth mobility and exfoliation of primary teeth and can be easily ignored, especially in cases that are not accompanied by a classic bone expansion. The present study aims to report a case of an 11 years old male child who, in the orthodontic evaluation, reported sensation in the mandibular teeth that would have been changing positions for approximately two months, without pain and with hypoesthesia in the lower lip. Computed tomography and incisional biopsy were performed to confirm the diagnosis and, subsequently, enucleation was performed followed by peripheral osteotomy under general anesthesia. It was concluded that the pathology is uncommon and has an unknown etiology. It is clear that, despite having benign biological behavior, it can be highly destructive, enabling different forms of surgical procedures. Its definitive diagnosis depends on evaluations through the analysis of clinical, radiographic, histopathological and serological exams, for an individualized approach within the presented clinical picture, similar to this report.
\end{abstract}


Keywords: Oral surgery; Enucleation; Oral pathology; Bone diseases.

\section{Resumen}

La lesión central de células gigantes (LCCG) es una lesión ósea no neoplásica que afecta a los huesos gnáticos en pacientes desde la primera infancia hasta la vejez, siendo más prevalente entre la segunda y la tercera década de la vida y entre las mujeres. LCCG muestra una variación de comportamiento agresivo y no agresivo, que puede reflejarse directamente en el tratamiento establecido. En pacientes pediátricos con dentición mixta, una lesión patológica puede ser la causa subyacente de la movilidad dentaria y / o exfoliación de los dientes temporales y puede descuidarse, especialmente en los casos que no se acompañan de una expansión ósea clásica. El presente estudio tiene como objetivo reportar el caso de un niño de 11 años de edad, quien en la evaluación ortodóncica refirió una sensación de movimiento en los dientes mandibulares por aproximadamente dos meses, sin dolor y con hipoestesia en el labio inferior. Se realizó tomografía computarizada y biopsia incisional para confirmar el diagnóstico y, posteriormente, enucleación, seguida de osteotomía periférica bajo anestesia general. Se concluyó que la patología es infrecuente y de etiología desconocida. Está claro que, a pesar de tener un comportamiento biológico benigno, puede ser altamente destructivo, permitiendo diferentes formas de procedimientos quirúrgicos. Su diagnóstico definitivo depende de evaluaciones a través del análisis de exámenes clínicos, radiográficos, histopatológicos y serológicos, para un abordaje individualizado dentro del cuadro clínico presentado, similar a este informe.

Palabras clave: Cirugía bucal; Enucleación; Patología bucal; Enfermedades de los huesos.

\section{Introdução}

A lesão central de células gigantes (LCCG), também chamada de granuloma central de células gigantes, foi descrita pela primeira vez em 1953 como uma lesão que acomete principalmente a maxila, mas também pode apresentar-se na mandíbula (Gupta et al., 2013; Lange \& Akker, 2005; Silva et al., 2018). Esta patologia intraóssea benigna é de caráter osteolítico e não apresenta características clínicas e radiográficas patognomônicas (Balaji \& Balaji, 2019; Novais et al., 2020).

A etiologia dessa entidade patológica é desconhecida, porém alguns fatores como o trauma e exodontias múltiplas, devem estar relacionados a essa lesão (Sarmento et al., 2011; Selden, 2000). Além disso, há indícios de que anormalidades genéticas estão implicadas (Lange \& Akker, 2005). A LCCG apresenta maior acometimento em adultos jovens e crianças, com predileção pelo gênero feminino, na proporção de 2:1 (Gupta et al., 2013). A literatura mostra que a lesão geralmente aparece antes dos 30 anos e ocorre duas vezes mais na mandíbula do que na maxila (Lange \& Akker, 2005; Curtis \& Walker, 2005). Nota-se ainda uma predileção pela região anterior dos ossos gnáticos (Neville et al., 2009; Novais et al., 2020; Lange \& Akker, 2005).

Um estudo realizado por Lange e Akker (2005) mostrou que a maioria dos pacientes eram assintomáticos. Outros autores corroboram abordando características como um aumento de volume indolor com assimetria facial perceptível, mobilidade dos elementos associados, e parestesia. É consenso que a característica mais comum é um aumento de volume da face ou na cavidade oral (Gupta et al., 2013; Sarmento et al., 2011).

As lesões diagnosticadas como não agressivas são aquelas que evoluem lentamente, são assintomáticas, não causam reabsorção radicular e não são recorrentes. Já as agressivas caracterizam-se por ter um crescimento rápido, dor, altas taxas de reabsorção radicular e elevado índice de recidiva (Balaji \& Balaji, 2019).

A aparência radiográfica pode ser de radiolucência unilocular ou multilocular, com expansão e destruição do osso circundante (Gupta et al., 2013; Selden, 2000). As características radiográficas podem variar apresentando lesões apicais pequenas a lesões destrutivas e extensas, reabsorção de raízes e deslocamento dentário (Lange \& Akker, 2005). As margens da lesão frequentemente não são corticalizadas (Novais et al., 2020; Selden, 2000).

Com base em suas características clínicas, radiográficas e histopatológicas determina-se o tratamento, visto que o direcionamento para a abordagem da lesão será com base na agressividade e extensão da mesma (Adornato \& Paticoff, 2001; Curtis \& Walker, 2005; Loureiro et al., 2019)

Segundo Sarmento et al. (2011) histologicamente essa lesão caracteriza-se pela proliferação de células redondas, fusiformes e/ou ovaladas, com numerosas células gigantes multinucleadas, dispersas em um estroma de tecido conjuntivo de 
densidade variável e, por vezes, intimamente associadas a vasos sanguíneos. Apresenta ausência de atipias e o extravasamento de eritrócitos e a deposição de hemossiderina frequentemente são predominantes. Ainda, a formação de osteóide por estar presente.

Como diagnósticos diferenciais destacam-se a Lesão Periférica de Células Gigantes, o Cisto Ósseo Aneurismático, Tumor Marrom do Hiperparatireoidismo (Neville et al., 2009; Novais et al., 2020; Sarmento et al., 2011; Silva et al., 2018).

Tradicionalmente, o tratamento usado é cirúrgico com curetagem agressiva que pode ser definida como uma abordagem direta da lesão. A ressecção deve ser o procedimento de escolha nos casos de lesões com características agressivas e recorrentes, sendo determinada como uma abordagem por meio da ressecção cirúrgica em bloco incluindo $5 \mathrm{~mm}$ de margem de tecido sadio (Balaji \& Balaji, 2019; Oliveira et al., 2017).

Citam-se ainda opções de tratamento não cirúrgico para a LCCG, incluindo o uso de esteróides intralesionais, calcitonina subcutânea ou nasal e injeções subcutâneas de interferon alfa (Balaji \& Balaji, 2019; Oliveira et al., 2017).

Balaji e Balaji (2019) relataram que a taxa de recidiva possui alta frequência em um curto período pós-operatório. A curetagem é o tratamento recomendado para lesões pequenas, mas apresenta risco de recorrência. A excisão radical é o tratamento de escolha quando a lesão é extensa e envolve o córtex, o que resulta na perda de elementos dentários. Sendo assim, em algumas situações desfavoráveis, a remoção dos dentes pode ser necessária.

\section{Metodologia}

Trata-se de um relato de caso, caracterizado como um estudo descritivo, exploratório e qualitativo (Pereira et al., 2018).

Foram seguidos os princípios éticos de pesquisa envolvendo seres humanos, sendo preservada a identidade do voluntário e fornecido todos os esclarecimentos sobre o tratamento, e posteriormente, após concordância do paciente a assinatura do Termo de Consentimento Livre Esclarecido (TCLE), consentindo o tratamento, a divulgação das imagens e dados coletados durante o atendimento clínico e os que constavam no prontuário, sendo que o mesmo poderia desistir da participação na pesquisa a qualquer momento.

\section{Relato de Caso}

Paciente do sexo masculino, 11 anos, compareceu acompanhado dos pais ao Serviço de Cirurgia Buco-maxilo-facial do Hospital Municipal do Tatuapé, após ser encaminhado da ortodontista. O paciente apresentava queixa de mobilidade dos dentes mandibulares há aproximadamente dois meses, sem sintomatologia dolorosa e com hipoestesia em lábio inferior esquerdo. Ao exame físico, foi observado um abaulamento da cortical óssea, deslocamento das raízes e alteração na inclinação das coroas dentárias (Figura 1). 
Figura 1: Aspecto extra oral com deslocamento dentário.

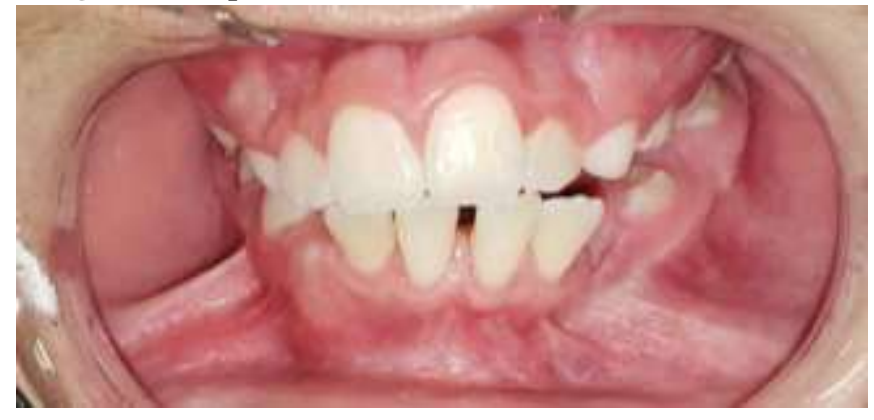

Fonte: Autores.

A documentação ortodôntica, revelou uma lesão radiolúcida causando deslocamento dentário e reabsorção de osso alveolar adjacente na região de canino e primeiro pré-molar inferior esquerdo (Figura 2).

Figura 2: Radiografia panorâmica da documentação ortodôntica.

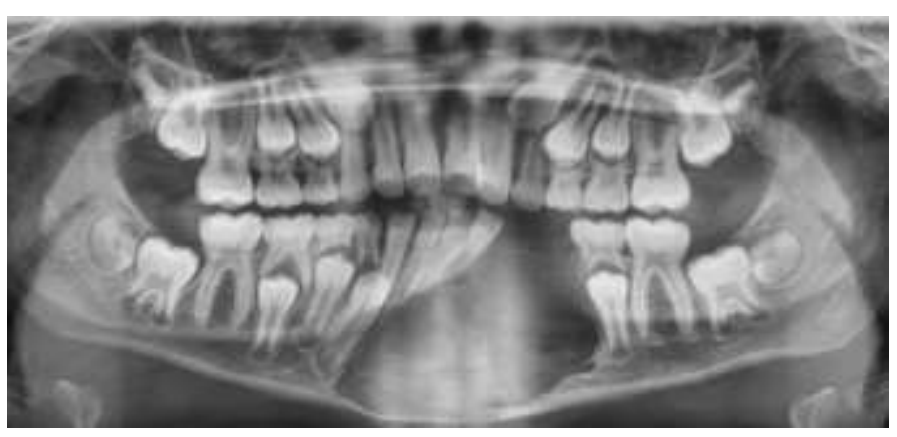

Fonte: Autores.

Foi realizada tomografia computadorizada que evidenciou uma lesão hipodensa, multiloculada, expansiva e com destruição da cortical óssea vestibular (Figura 3,4).

Figura 3: Tomografia Computadorizada - Corte panorâmico.

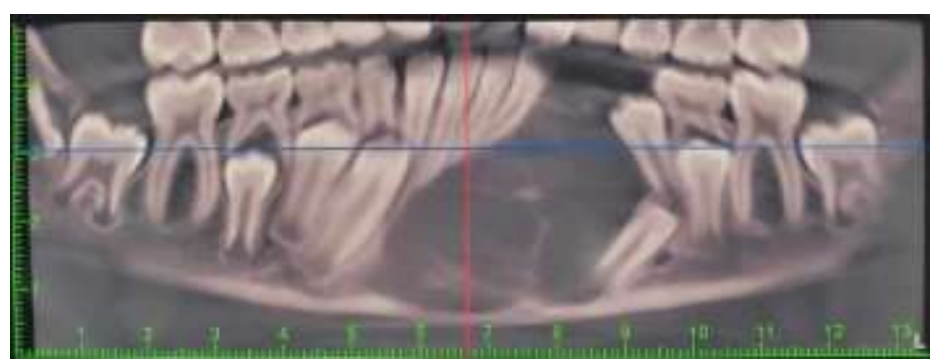

Fonte: Autores. 
Figura 4: Tomografia computadorida - Cortes axiais.

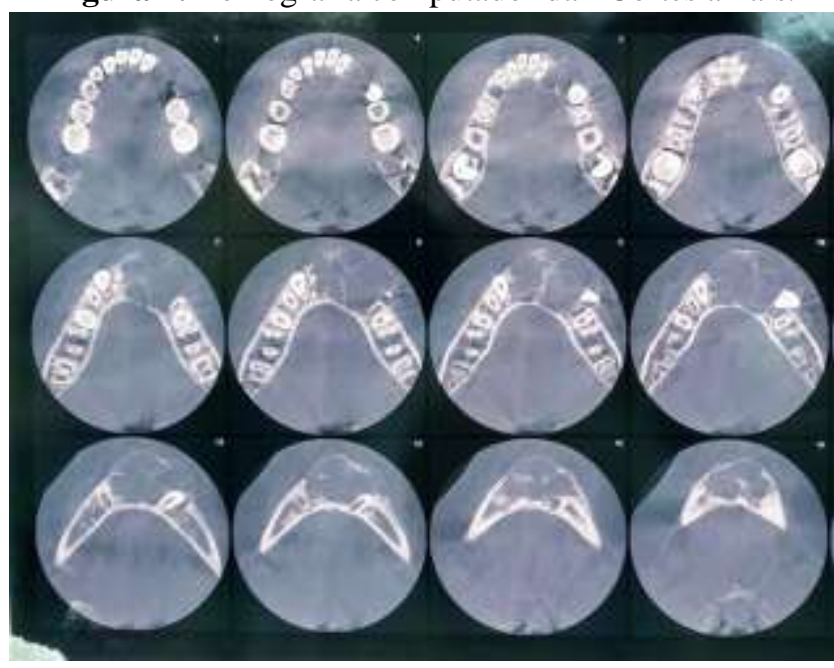

Fonte: Autores.

Diante do quadro clínico e radiográfico foi estabelecido como hipótese diagnóstica a LCCG ou o cisto ósseo aneurismático. Sendo assim, o paciente foi submetido a biópsia incisional, o espécime foi removido e armazenado em formaldeído 10\%, enviado para exame anatomopatológico e confirmado o diagnóstico de LCCG.

A abordagem cirúrgica foi por meio de enucleação seguida de osteotomia periférica sob anestesia geral (Figura 5,6). No pós operatório de 15 dias observou-se deiscência da sutura, logo, utilizou-se um protocolo de irrigação três vezes ao dia com digluconato de clorexidina $0,12 \%$ proporcionando o fechamento do defeito em aproximadamente 40 dias (Figura 7 ).

Figura 5: A- Exposição do leito cirúrgico; B-Enucleação da lesão.

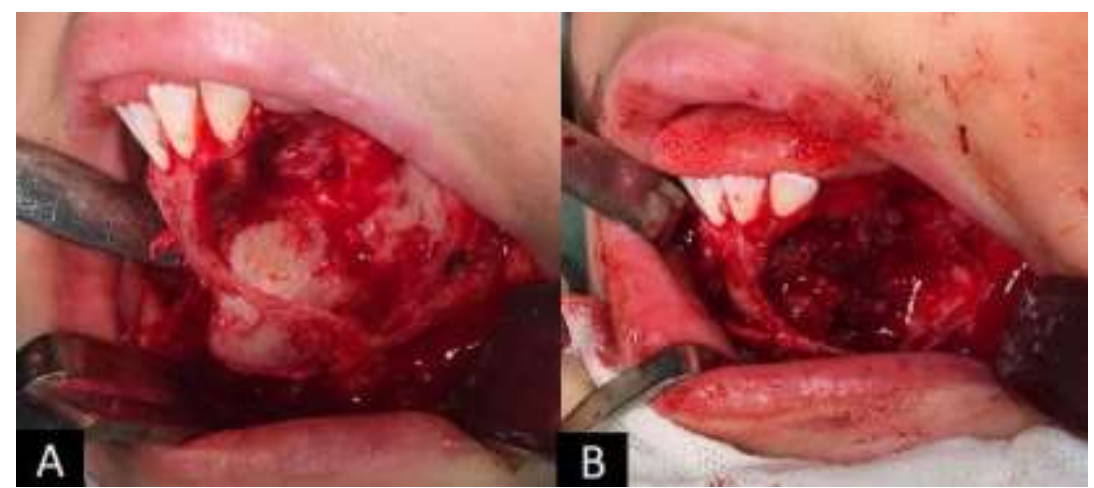

Fonte: Autores. 
Research, Society and Development, v. 10, n. 2, e43610212742, 2021

(CC BY 4.0) | ISSN 2525-3409 | DOI: http://dx.doi.org/10.33448/rsd-v10i2.12742

Figura 6: Peça cirúrgica removida com os elementos dentários: cápsula da lesão aderida ao dente.

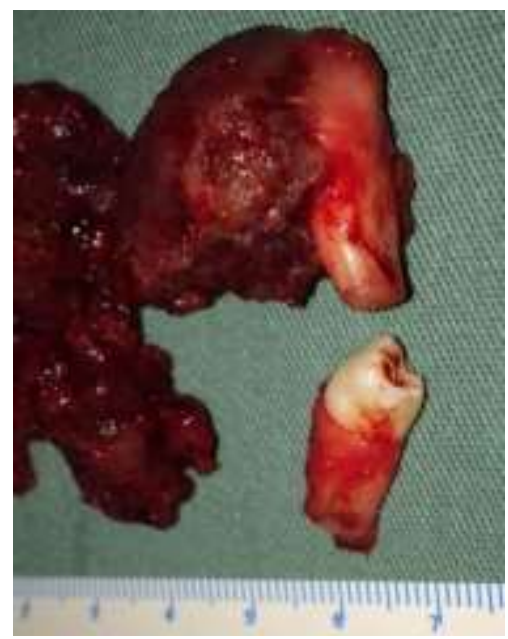

Fonte: Autores.

Figura 7: Cicatrização da lesão.

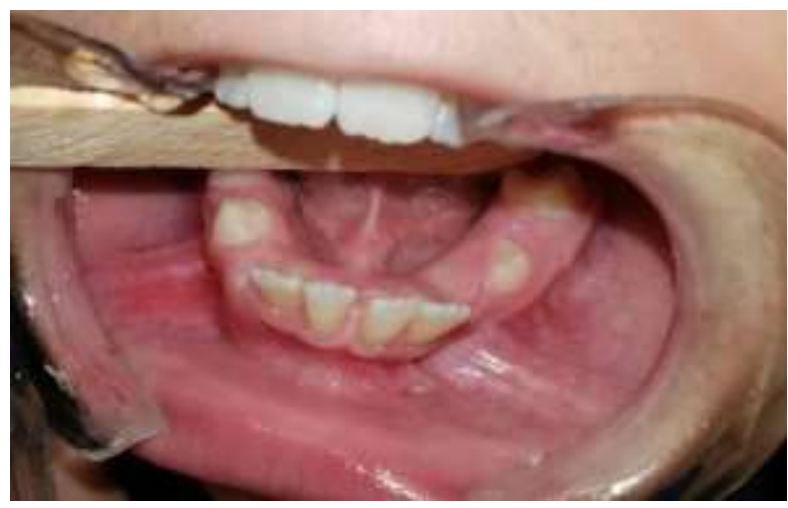

Fonte: Autores.

No acompanhamento radiográfico pós operatório de 12 meses notou-se margens da loja cirúrgica escleróticas, sugestivas de neoformação óssea (Figura 8). O paciente evoluiu sem parestesia do nervo alveolar inferior e resolução total da deiscência da mucosa oral.

Figura 8: Radiografia panorâmica do pós operatório de 12 meses.

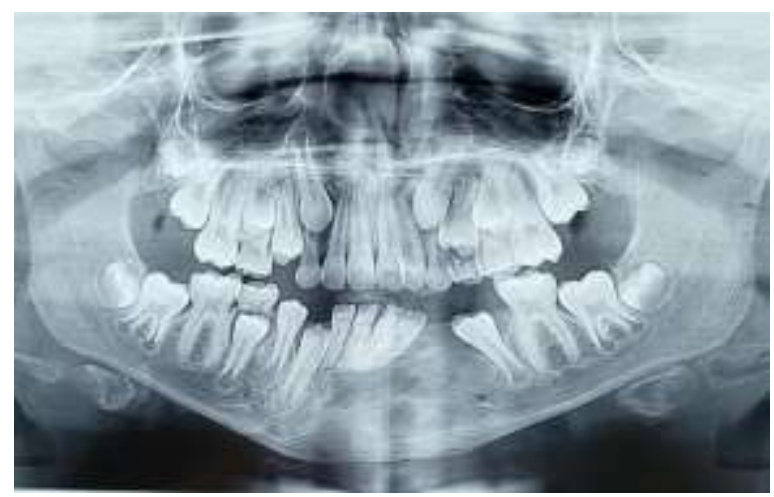

Fonte: Autores. 


\section{Discussão}

Diversos autores afirmam que LCCG é mais comum em pacientes do gênero feminino e com menos de 30 anos de idade (Balaji \& Balaji, 2019; Curtis \& Walker, 2005; Duarte et al., 2007; Gupta et al., 2013; Lange \& Akker, 2005; Selden, 2000; Sarmento et al., 2011). Neste caso clínico, observa-se, um paciente do gênero masculino de 11 anos.

Segundo Gupta et al. (2013) o envolvimento mandibular é mais frequente em 6,5\% dos pacientes comparado a maxila. Além disso, a maioria dessas lesões estão localizadas cruzando a linha média, como é relatado neste estudo.

A etiologia das LCCG ainda é obscura, porém o trauma pode estar relacionado a essa patologia (Lange \& Akker, 2005; Neville et al., 2009; Sarmento et al., 2011). Neste relato a descoberta foi durante a anamnese realizada em uma avaliação ortodôntica.

Frequentemente é uma lesão assintomática descoberta durante exames radiográficos de rotina, ou quando ocorre expansão indolor do osso afetado sendo assim, notado pelo paciente ou pelos pais. No entanto, é relatado que 5-11\% das lesões são sintomáticas (Neville et al., 2009; Mohan et al., 2013). Contudo, neste caso, a lesão foi descoberta ainda sem apresentar dor.

Em crianças com dentição mista, uma lesão patológica pode ser a causa implícita da mobilidade dentária e esfoliação dos dentes decíduos, podendo ser facilmente despercebida, especialmente nos casos que não são acompanhados por uma expansão óssea. Essas causas frequentemente complicam a análise radiográfica e podem atrasar o diagnóstico e agravar o caso (Silva et al., 2018; Mohan et al., 2013).

Radiograficamente, nota-se uma radiolucência multilocular, com expansão e destruição do osso circundante, consoando a literatura. Com base na histologia, as características da LCCG são geralmente representadas por células mononucleadas e multinucleadas que podem estar acompanhadas de um infiltrado inflamatório (Gupta et al., 2013; Sarmento et al., 2011).

Em pacientes que apresentam múltiplas lesões de células gigantes, uma avaliação genética deve ser efetuada, para se eliminar ou detectar a hipótese de Síndrome de Noonan ou Síndrome das Múltiplas Lesões de Células Gigantes, caracterizada por doenças cardíacas congênitas, estenose pulmonar, ptose, hipertelorismo, micrognatia e baixa estatura, entre outros aspectos (Edwards et al., 2005; Silva et al., 2018). No caso relatado não foi diagnosticada nenhuma característica facial, tampouco história de patologia cardíaca.

Diante do diagnóstico histopatológico de LCCG, é extremamente aconselhável a realização de exames sorológicos para avaliação dos valores de hormônio da paratireóide (PTH), cálcio sérico, fosfatase alcalina e níveis de fósforo para investigação de um possível quadro de hiperparatireoidismo, uma vez que a apresentação clínica, radiográfica e histopatológica da LCCG são indistinguíveis do tumor marrom do hiperparatireoidismo (Loureiro et al., 2019; Mohan et al., 2013).

A cirurgia é o método mais tradicional para o tratamento da LCCG (Balaji \& Balaji, 2019; Gupta et al., 2013; Oliveira et al., 2017). Neste caso o tratamento foi a enucleação com a osteotomia periférica. Associado ao tratamento foi utilizado um antisséptico químico com ação antifúngica e bactericida para atenuar os efeitos do pós-operatório.

Outros métodos de tratamento como os esteróides e a calcitonina têm sido preconizados e agem pela inibição da atividade osteoclástica. Partes iguais de acetonido de triancinolona $(10 \mathrm{mg} / \mathrm{mL})$ e bupivacaína a $0,5 \%$ injetadas na lesão por um período de 11 semanas demonstraram ser eficazes em uma criança. Existem contraindicações relativas em certas condições, como diabetes mellitus, úlcera péptica e estados imunocomprometidos generalizados (Novais et al., 2020; Mohan et al., 2013).

Há relatos que o spray nasal de calcitonina 200U/ spray uma ou duas vezes ao dia é seguro e eficaz para o tratamento de LCCG. Porém, a terapia pode ser complicada devido à grande quantidade de desconforto e à duração relativamente longa do tratamento, com pouca adesão as crianças. Em locais que a cirurgia é conservadora, interferon subcutâneo diário $\alpha$ (3 milhões de unidades $/ \mathrm{m} 2$ da área da superfície corporal) foi analisado como adjuvante devido às suas propriedades antiangiogênicas; 
mas efeitos colaterais significativos podem limitar sua utilidade. Foi demonstrado que uma combinação de interferon $\alpha$ e imatinibe administrado por 9 meses inicia-se a regressão da lesão que continuou após o término do tratamento. Os bisfosfonatos também foram tentados por via intravenosa com resultados promissores. $\mathrm{O}$ tratamento com radiação é contra-indicado devido ao potencial de transformação maligna (Loureiro et al., 2019; Mohan et al., 2013).

Por fim, destacamos o uso da bola de Bichat ou corpo adiposo da bochecha no reparo desses tipos de lesões. Esse método reconstrutivo foi escolhido por ser uma técnica simples, ter uma grande semelhança com o defeito cirúrgico e é altamente confiável; não há sequelas, possui resultados funcionais excelentes, graças metaplasia desenvolvida pela gordura, que é praticamente indistinguível da mucosa oral adjacente (Duarte et al., 2007).

\section{Considerações Finais}

Diante do exposto, conclui-se que a LCCG é uma patologia pouco frequente e possui etiologia desconhecida. É notório que, apesar de possuir comportamento biológico benigno, pode ser altamente destrutiva. O diagnóstico, prognóstico e grau de agressividade da LCCG são de extrema importância para o Cirurgião-Dentista determinar a abordagem mais eficaz e benéfica ao paciente.

O tratamento pode variar as formas de abordagens de acordo com o comportamento invasivo ou não invasivo, por meio de medicamentos e abordagem cirúrgica. Seu diagnóstico definitivo depende de avaliações que devem ser estudadas cautelosamente através da análise de exames clínicos, radiográficos, histopatológicos e sorológicos. E assim, elege-se o tratamento elaborado de acordo com as peculiaridades de cada indivíduo.

Ademais, sugere-se a realização de mais pesquisas para comprovar a efetividade de meios de tratamentos não cirúrgico para a LCCG, incluindo o uso de esteróides intralesionais, calcitonina subcutânea ou nasal e injeções subcutâneas de interferon alfa.

\section{Referências}

Adornato, M. C., \& Paticoff, K. A. (2001). Intralesional corticosteroid injection for treatment of central giant-cell granuloma. J Am Dent Assoc, 132(2), 186190 .

Balaji, P., \& Balaji, S. M. (2019). Central giant cell granuloma - A case report. Indian J Dent Res, 30(1), 130-132.

Curtis, N. J., \& Walker, D. M. (2005). A case of aggressive multiple metachronous central giant cell granulomas of the jaws: differential diagnosis and management options. Int J Oral Maxillofac Surg, 34(7), 806-808.

Duarte, R. B., Garcia, F. A. R., Cuéllar, C. N., Bucci, T., Gil, M. C., \& Vila, C. N. (2007). Reparative giant cell granuloma in a pediatric patient. Med Oral Patol Oral Cir Bucal, 12(4), 331-335.

Edwards, P. C., Fox, J., Fantasia, J. E., Goldberg, J., \& Kelsch, R. D. (2005). Bilateral central giant cell granulomas of the mandible in an 8-year-old girl with Noonan syndrome (Noonan-like/multiple giant cell lesion syndrome). Oral Surg Oral Med Oral Pathol Oral Radiol Endod, 99(3), 334-340.

Gupta, M., Gupta, M., Singh, S., \& Kaur, R. (2013). Central giant cell granuloma of the maxilla. BMJ Case Rep, 9(102), 1-5.

Lange, J. D., \& Akker, H. P. (2005). Clinical and radiological features of central giant-cell lesions of the jaw. Oral Surg Oral Med Oral Pathol Oral Radiol Endod. 99(4), 464-470.

Loureiro, A. M. L. C., Silva, C. L. S., Nunes, L. S. O., Theotonio, P. E. S., Santana, S. F., \& Franco, A. V. M. F. (2019). Abordagem farmacológica em lesão central de células gigantes: Relato de caso. Revista Eletrônica Acervo Saúde, 37(2111), 1-7.

Mohan, R. P., Verma, S., Agarwal, N., \& Singh, U. (2013). Central giant cell granuloma: a case report. BMJ Case Rep, 2(1), 41-45.

Novais, M. P. S., Vasconcelos, L. S., Lima, L. B., Loyola, A. M., \& Paulo, L. F. B. (2020). Lesão de células gigante: abordagem diagnóstica e terapêutica: Um relato de caso. Anais da jornada odontológica da FPM, 4(2), 73.

Neville, B. W., Damm, D. D., Allen, C. M., \& Bouquot, J. E. (2009). Patologia Oral e Maxilofacial. Elsevier.

Oliveira, J. P., Olivete, F., Oliveira, N. D., Giovanini, A. F., Zielak, J. C., Klüppel, L., \& Scariot, R. (2017). Combination therapies for the treatment of recurrent central giant cell lesion in the maxilla: a case report. J Med Case Rep, 11(1), 74. 
Research, Society and Development, v. 10, n. 2, e43610212742, 2021

(CC BY 4.0) | ISSN 2525-3409 | DOI: http://dx.doi.org/10.33448/rsd-v10i2.12742

Pereira, A. S., Shitsuka, D. M., Parreira, F. J. \& Shitsuka, R. (2018). Metodologia da pesquisa científica. UFSM. https://repositorio.ufsm.br/bitstream/han dle/1/15824/Lic Computacao_Metodologia-Pesquisa-Cientifica.pdf?sequence=1

Sarmento, D. J., Santos, J. A., Lima, L. H., Lima, M. G., \& Godoy, G. P. (2011). Tratamento cirúrgico de lesão central de células gigantes na maxila: relato de caso. Braz JOtorhinolaryngol. 77(1), 136.

Selden, H. S. (2000). Central giant cell granuloma: a troublesome lesion. J Endod, 26(6), 371-373.

Silva, W. S. A., Moreira, G., Marques, I. P. M., \& Silva, A. F. (2018). Lesão central de células gigantes - Relato de caso. Revista Eletrônica Acervo Saúde, 17(192), 1-9. 